\title{
AVASCULAR NECROSIS OF THE FEMORAL HEAD
}

\author{
NATURAL HISTORY AND MAGNETIC RESONANCE IMAGING
}

YOSHIO TAKATORI, TAKASHI KOKUBO, SETSUO NINOMIYA, SHIGERU NAKAMURA, SHUHEI MORIMOTO, IKUO KUSABA

From The University of Tokyo, Japan

We studied the prognostic value of MRI in 32 radiographically normal, asymptomatic hips in 25 patients at risk of osteonecrosis from glucocorticoids or alcoholism. The early findings were band-like hypointense zones on spin-echo images.

No operations were performed. Life-table survival curves showed that femoral heads in which the hypointense zone traversed the middle portion of the head were most at risk of subsequent segmental collapse.

J Bone Joint Surg [Br] 1993; 75-B:217-21.

Received 29 April 1992; Accepted 17 August 1992
Segmental collapse frequently occurs in a femoral head affected with osteonecrosis. The sensitivity of MRI in its early diagnosis, when radiological changes are not apparent, has been established (Robinson et al 1989; Stulberg et al 1989).

One of the most common MR findings is an area of 'fat intensity' similar to that of subcutaneous fat tissue and proximal to a band-like hypointense zone (Mitchell et al 1989; Kokubo et al 1992). Histological studies have shown that this hypointense zone demarcates the proximal necrotic lesion (Bassett et al 1987; Lang et al 1988; Mitchell et al 1989). This allows the site and the extent of the necrotic lesion which is implicated in the fate of the femoral head (Merle d'Aubigné et al 1965; Glimcher and Kenzora 1979), to be determined from MR findings.

We have made a prospective study of the prognostic value of MRI in the early stage of the disease, using a life-table survival-curve method.

\section{PATIENTS AND METHODS}

From 1984 to 1991, at the University of Tokyo Hospital, we evaluated 25 consecutive patients with 32 asymptomatic hips in which spin-echo (SE) MRI showed bandlike hypointense zones. None of the hips had any abnormalities on plain anteroposterior and lateral radiographs taken at the time of MRI.

The mean age of the patients was 41 years (16 to $80)$; ten were men and 15 were women. The patients were at risk of avascular necrosis from the use of glucocorticoids (19 patients: 26 hips) or from alcoholism (5 patients; 5 hips).

MRI was performed with a 1.5 Tesla Magnetom unit (Siemens AG, Erlangen, Germany). Images were reconstructed by the two-dimensional Fourier transformation technique. The matrix size was $256 \times 256$. Multislice SE images were obtained in the coronal and axial planes with $10 \mathrm{~mm}$ slice thickness, two excitations, a TR (repetition time) of $600 \mathrm{~ms}$ and a TE (echo time) of 35,28 or $23 \mathrm{~ms}$. In addition, sagittal images were obtained at the level of the centre of the femoral head using the same pulse sequences. 
The MR images were classified into four types on the basis of the site and the extent of the fat intensity area proximal to the band-like hypointense zone (Takatori et al 1991).

Type $A$. The fat intensity area was confined to the medial anterosuperior portion of the femoral head (Fig. 1). The band-like hypointense zone did not extend beyond the zenith of the femoral head on the mid-sagittal MR scan. Type $B$. The fat intensity area was intermediate between that of type A and type C (Fig. 2). The posterior end of

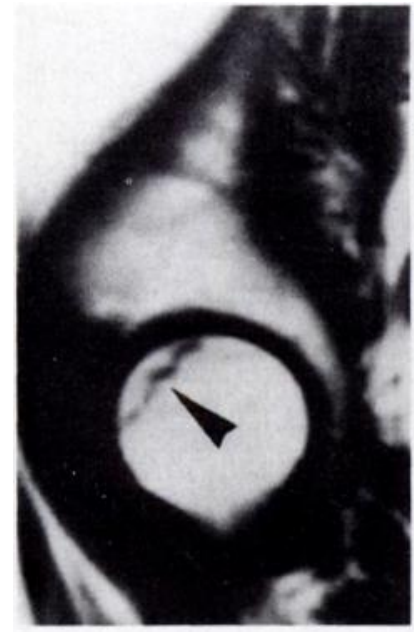

Fig. 1a

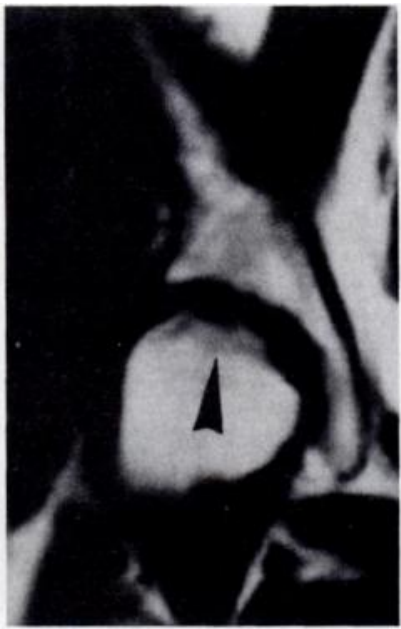

Fig. 1b

The relationship between the four types is shown in Figure 5.

On the basis of the MR findings two groups of femoral heads were identified. Type A heads were classified into group I and types B, C and D into group II. There were 15 hips in group I and 17 in group II (Tables I, II).

The patients were kept under observation, without core decompression or biopsy, and the progress of the disease was checked radiographically.

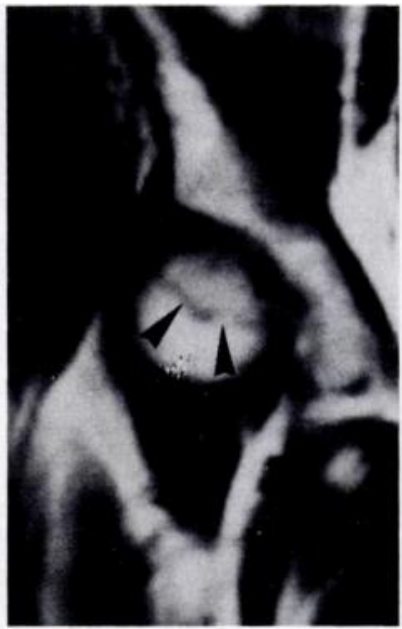

Fig. 1c

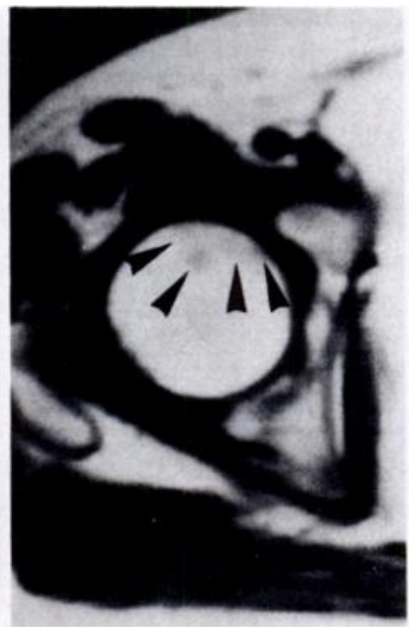

Fig. 1d

Type A. Case 8. Spin-echo MRI (SE 600/23) showing: a) sagittal image, b) mid-coronal image, c) coronal image of the anterior portion of the femoral head and d) axial image.

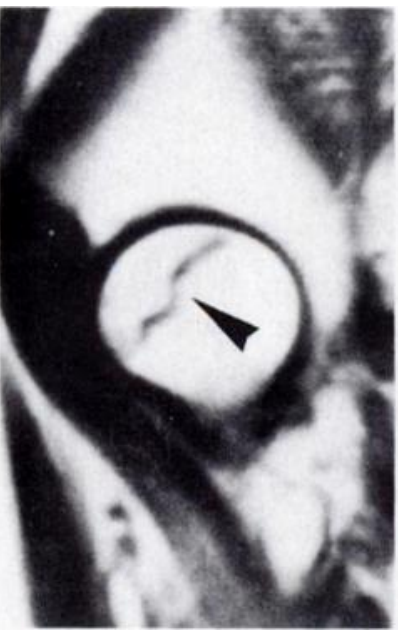

Fig. 2a

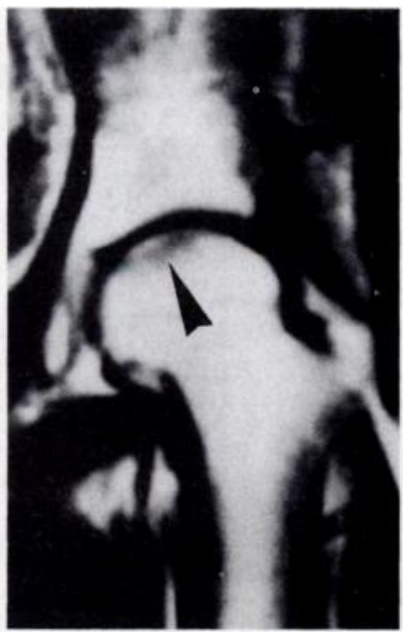

Fig. 2b

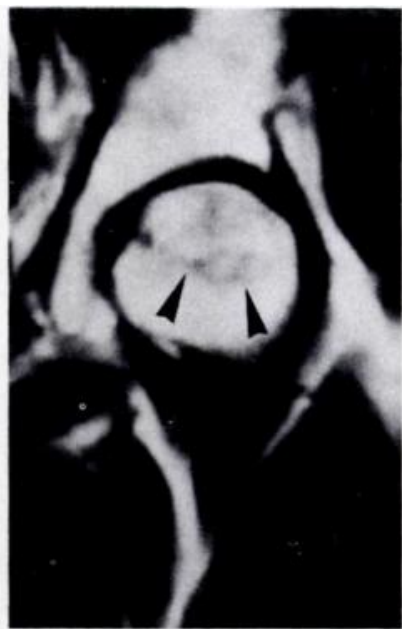

Fig. 2c

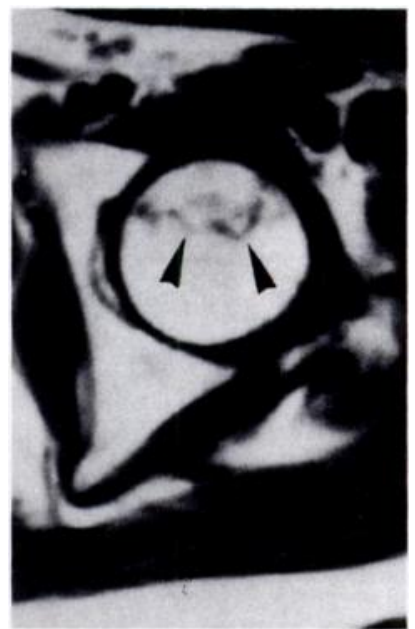

Fig. 2d

Type B. Case 19. Spin-echo MRI (SE 600/23) showing: a) sagittal image, b) mid-coronal image, c) coronal image of the anterior portion of the femoral head and d) axial image.

the band-like hypointense zone lay between the zenith and the posterior edge of the femoral head on the midsagittal image.

Type $C$. The fat intensity area occupied the proximal half of the femoral head (Fig. 3). The band-like hypointense zone traversed the middle portion of the femoral head horizontally on the mid-coronal and mid-sagittal images. Type $D$. The fat intensity area was larger than that of type C (Fig. 4).
The content and timing of segmental collapse were recorded as survival time from MRI diagnosis. A life table and survival curves were constructed using the standard error of a percentage from the formula:

$$
\sqrt{\frac{p \times(100-p)}{n}}
$$

where $\mathrm{p}$ is the survival rate expressed as a percentage 


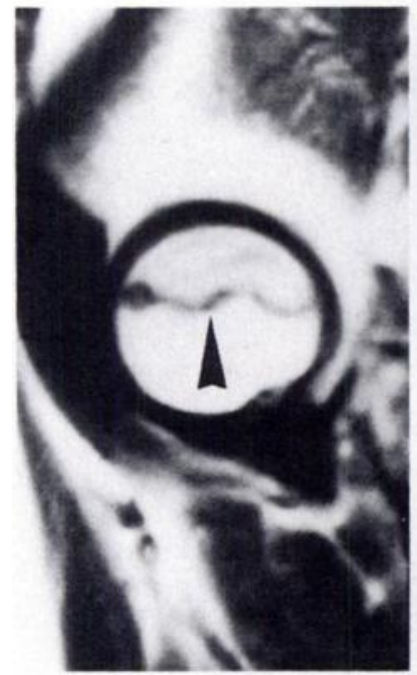

Fig. 3a

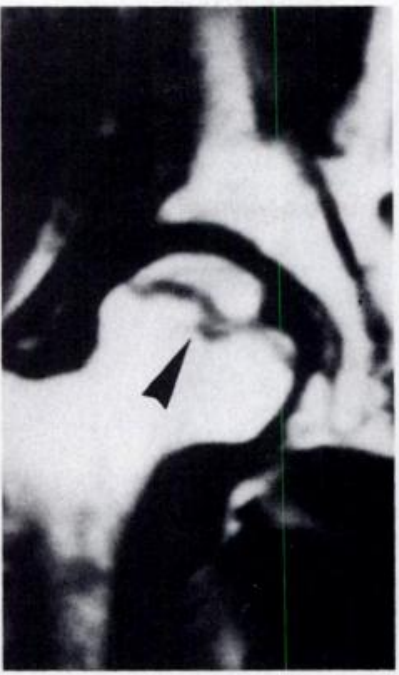

Fig. 3b

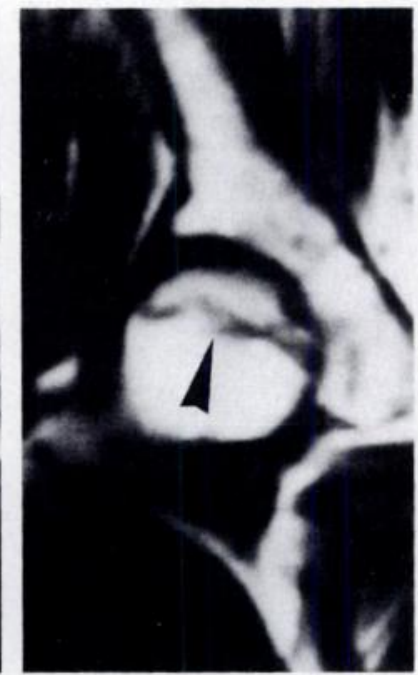

Fig. 3c

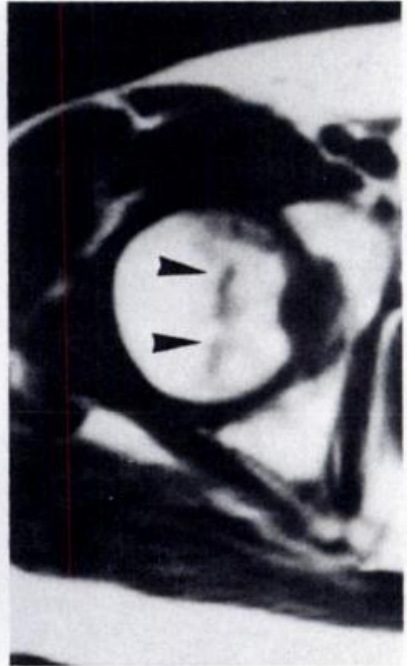

Fig. 3d

Type C. Case 22. Spin-echo MRI (SE 600/23) showing: a) sagittal image, b) mid-coronal image, c) coronal image of the anterior portion of the femoral head and d) axial image.

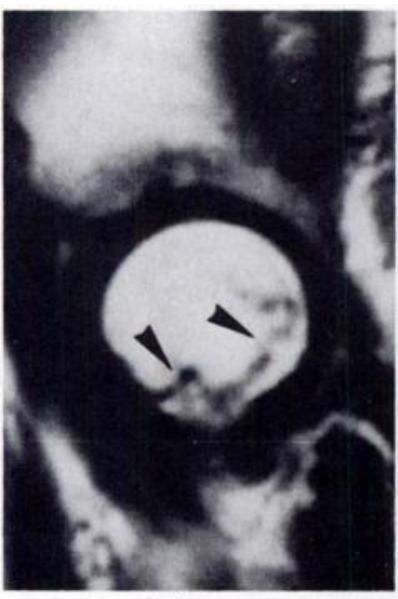

Fig. $4 \mathrm{a}$

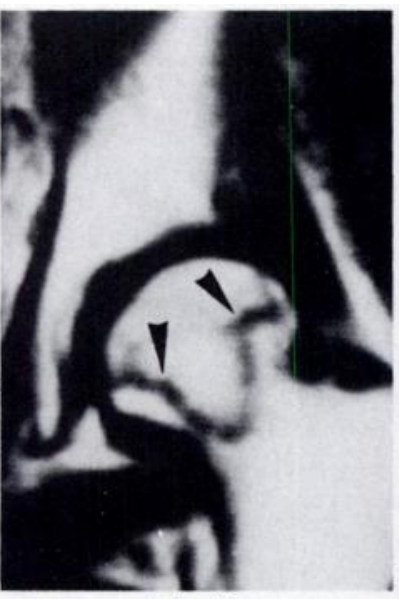

Fig. 4b

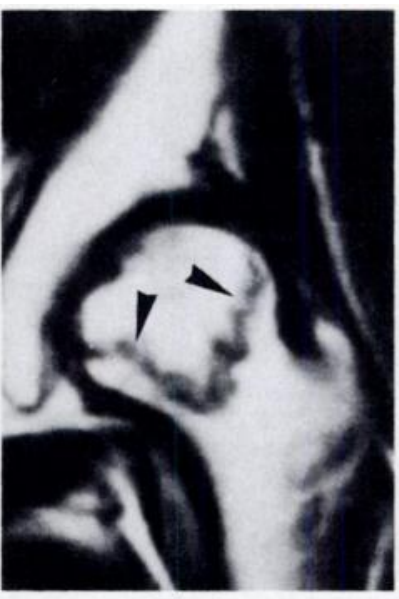

Fig. 4c

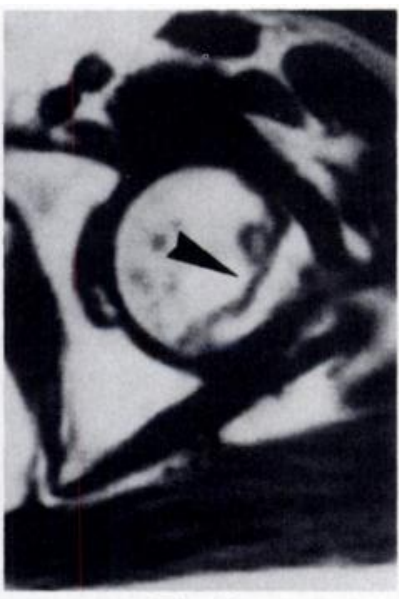

Fig. $4 \mathrm{~d}$

Type D. Case 24. Spin-echo MRI (SE 600/23) showing: a) sagittal image, b) mid-coronal image, c) coronal image of the anterior portion of the femoral head and d) axial image.

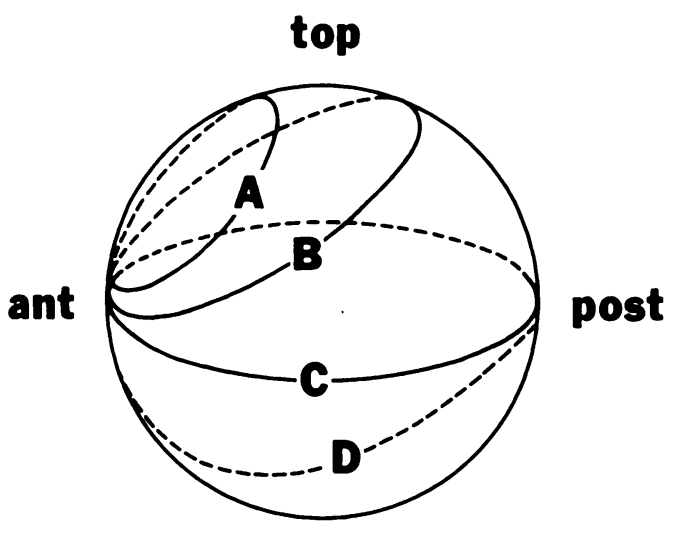

Fig. 5

Diagram to show the zones involved on MRI by the four types of avascular necrosis (see text). and $\mathrm{n}$ is the number of femoral heads at risk at the time of the estimation (Pocock 1983).

\section{RESULTS}

There were no cases of subsequent segmental collapse in group I; there were 14 cases in group II (Table III, Fig. 6). The mean time between MRI and collapse was 15 months ( 2 to 43 ). It was clear that the risk of segmental collapse was significantly higher in group II femoral heads than in group $I$.

\section{DISCUSSION}

Segmental collapse of the femoral head is the most important factor in the prognosis of patients with avascular necrosis. Surgeons must therefore be aware not only of the presence of osteonecrosis, but also of the probable fate of the affected femoral head without treatment. In some cases, radiological findings have been reported to give an accurate prognosis for individual 
Table I. Details of patients with group I femoral heads

\begin{tabular}{|c|c|c|c|c|c|c|}
\hline Case & $\begin{array}{l}\text { Age } \\
(\mathbf{y r})\end{array}$ & Sex & Side & $\begin{array}{l}\text { Interval between } \\
\text { starting steroids } \\
\text { and MRI }\end{array}$ & $\begin{array}{l}\text { Pattern } \\
\text { of MRI }\end{array}$ & Associated conditions \\
\hline 1 & 46 & $\mathbf{M}$ & $\mathbf{R}$ & Not used & $\mathbf{A}$ & Alcoholism \\
\hline 2 & 38 & $\mathbf{F}$ & $\mathbf{R}$ & 6 yrs & $\mathbf{A}$ & SLE* \\
\hline 3 & 58 & $\mathbf{F}$ & $\mathbf{R}$ & 7 yrs $7 \mathrm{mths}$ & $\mathbf{A}$ & Multiple sclerosis \\
\hline 4 & 37 & $\mathbf{F}$ & $\mathbf{L}$ & 21 yrs & $\mathbf{A}$ & SLE \\
\hline 5 & 42 & $\mathbf{F}$ & $\begin{array}{l}\mathbf{R} \\
\mathbf{L}\end{array}$ & $\begin{array}{l}6 \text { yrs } 10 \text { mths } \\
6 \text { yrs } 10 \text { mths }\end{array}$ & $\begin{array}{l}\mathbf{A} \\
\mathbf{A}\end{array}$ & SLE \\
\hline 6 & 46 & $\mathbf{F}$ & $\mathbf{R}$ & 2 yrs 3 mths & $\mathbf{A}$ & SLE \\
\hline 7 & 40 & $\mathbf{M}$ & $\mathbf{L}$ & Not used & $\mathbf{A}$ & Alcoholism \\
\hline 8 & 16 & $\mathbf{F}$ & $\begin{array}{l}\mathbf{R} \\
\mathbf{L}\end{array}$ & $\begin{array}{l}1 \mathrm{yr} 7 \mathrm{mths} \\
1 \mathrm{yr} 7 \mathrm{mths}\end{array}$ & $\mathbf{A}$ & Dermatomyositis \\
\hline 9 & 49 & $\mathbf{F}$ & $\begin{array}{l}\mathbf{R} \\
\mathbf{L}\end{array}$ & $\begin{array}{l}7 \text { yrs } \\
7 \text { yrs }\end{array}$ & $\begin{array}{l}\mathbf{A} \\
\mathbf{A}\end{array}$ & SLE \\
\hline 10 & 69 & $\mathbf{M}$ & $\mathbf{R}$ & Not used & $\mathbf{A}$ & Alcoholism \\
\hline 11 & 49 & $\mathbf{F}$ & $\begin{array}{l}\mathbf{R} \\
\mathbf{L}\end{array}$ & $\begin{array}{l}13 \mathrm{yrs} \\
13 \mathrm{yrs}\end{array}$ & $\begin{array}{l}A \\
A\end{array}$ & SLE \\
\hline
\end{tabular}

* systemic lupus erythematosus

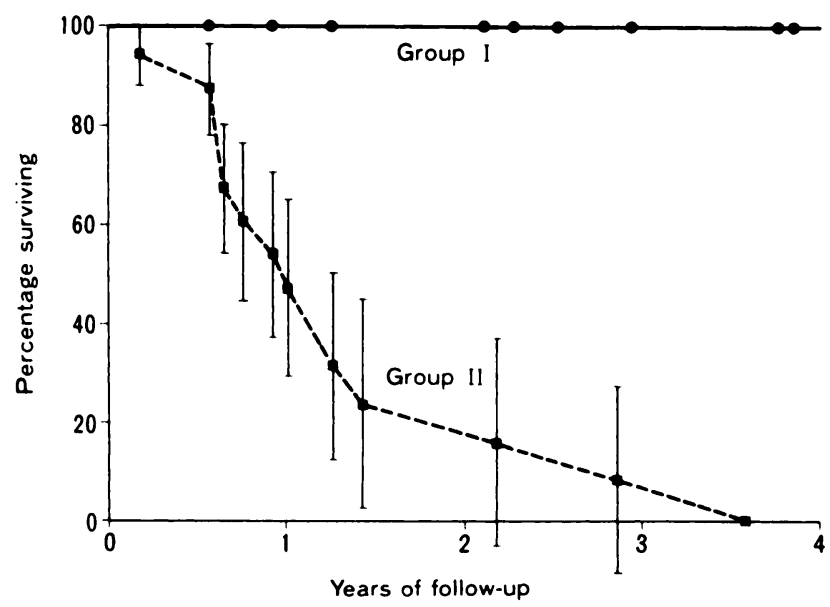

Fig. 6

Life-table survival curves with standard error for group I (type A) and group II (types B, C and D) femoral heads.

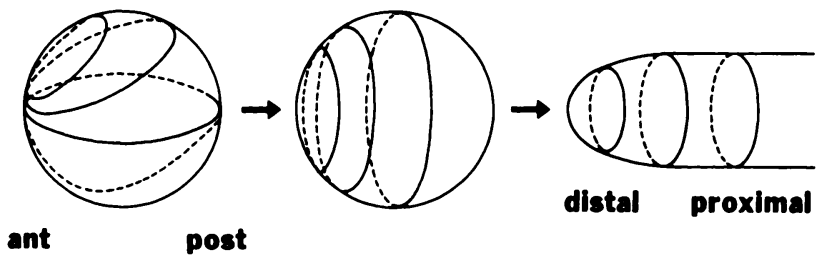

Fig. 7

Diagram to illustrate the analogy between the site and the extent of necrotic lesions in the femoral head and those in an ischaemic limb. Decrease in blood flow causes necrosis which starts from the periphery of the circulation.
Table II. Details of patients with group II femoral heads

\begin{tabular}{|c|c|c|c|c|c|c|}
\hline Case & $\begin{array}{l}\text { Age } \\
\text { (yr) }\end{array}$ & Sex & Side & $\begin{array}{l}\text { Interval between } \\
\text { starting steroids } \\
\text { and MRI }\end{array}$ & $\begin{array}{l}\text { Patterm } \\
\text { of MRI } \\
\end{array}$ & Associated conditions \\
\hline 12 & 39 & $\mathbf{M}$ & $\begin{array}{l}\mathbf{R} \\
\mathbf{L}\end{array}$ & $\begin{array}{l}4 \mathrm{mths} \\
4 \mathrm{mths}\end{array}$ & $\begin{array}{l}\mathrm{C} \\
\mathrm{C}\end{array}$ & $\begin{array}{l}\text { Renal } \\
\text { transplantation }\end{array}$ \\
\hline 13 & 48 & $\mathbf{F}$ & L & $1 \mathrm{yr} 10 \mathrm{mths}$ & B & ITP* \\
\hline 14 & 18 & $\mathbf{M}$ & $\mathbf{R}$ & $1 \mathrm{yr} 11 \mathrm{mths}$ & $\mathrm{C}$ & ALL† \\
\hline 15 & 31 & $\mathbf{F}$ & L & 5 yrs & D & SLE $\ddagger$ \\
\hline 16 & 27 & $\mathbf{F}$ & $\mathbf{R}$ & 2 yrs & B & SLE \\
\hline 17 & 21 & $\mathbf{M}$ & $\mathbf{R}$ & $11 \mathrm{mths}$ & $\mathrm{C}$ & SLE \\
\hline 6 & 46 & $\mathbf{F}$ & L & 2 yrs $3 \mathrm{mths}$ & D & SLE \\
\hline 18 & 21 & $\mathbf{M}$ & $\mathbf{L}$ & 8 yrs & B & SLE \\
\hline 19 & 23 & $\mathbf{F}$ & $\mathrm{L}$ & 5 yrs & B & SLE \\
\hline 20 & 39 & $\mathbf{M}$ & L & Not used & B & Alcoholism \\
\hline 21 & 56 & $\mathbf{M}$ & $\mathbf{R}$ & Not used & B & Alcoholism \\
\hline 22 & 47 & $\mathbf{F}$ & $\mathrm{L}$ & $8 \mathrm{yrs}$ & $\mathrm{C}$ & SLE \\
\hline 23 & 37 & $\mathbf{F}$ & $\mathbf{R}$ & $15 \mathrm{yrs}$ & D & SLE \\
\hline 24 & 47 & $\mathbf{F}$ & $\begin{array}{l}\mathbf{R} \\
\mathbf{L}\end{array}$ & $\begin{array}{l}7 \mathrm{yrs} \\
7 \mathrm{yrs}\end{array}$ & $\begin{array}{l}\mathrm{D} \\
\mathrm{D}\end{array}$ & $\begin{array}{l}\text { SLE } \\
\text { SLE }\end{array}$ \\
\hline 25 & 80 & $\mathbf{M}$ & $\mathbf{R}$ & Not used & C & None \\
\hline
\end{tabular}

* idiopathic thrombocytopenic purpura

$\dagger$ acute lymphocytic leukaemia

$\ddagger$ systemic lupus erythematosus

Table III. Follow-up and result for 32 femoral heads related to MRI group (C= collapsed, $\mathbf{N}=$ not collapsed)

\begin{tabular}{llll}
\hline Group I (mth) & Group II (mth) \\
\hline 6 & $\mathrm{~N}$ & 2 & $\mathrm{C}$ \\
6 & $\mathrm{~N}$ & 3 & $\mathrm{~N}$ \\
11 & $\mathrm{~N}$ & 4 & $\mathrm{~N}$ \\
15 & $\mathrm{~N}$ & 6 & $\mathrm{C}$ \\
15 & $\mathrm{~N}$ & 7 & $\mathrm{C}$ \\
25 & $\mathrm{~N}$ & 7 & $\mathrm{C}$ \\
25 & $\mathrm{~N}$ & 7 & $\mathrm{C}$ \\
27 & $\mathrm{~N}$ & 9 & $\mathrm{C}$ \\
30 & $\mathrm{~N}$ & 11 & $\mathrm{C}$ \\
35 & $\mathrm{~N}$ & 12 & $\mathrm{C}$ \\
35 & $\mathrm{~N}$ & 15 & $\mathrm{~N}$ \\
45 & $\mathrm{~N}$ & 15 & $\mathrm{C}$ \\
46 & $\mathrm{~N}$ & 15 & $\mathrm{C}$ \\
57 & $\mathrm{~N}$ & 17 & $\mathrm{C}$ \\
62 & $\mathrm{~N}$ & 26 & $\mathrm{C}$ \\
& & 31 & $\mathrm{C}$ \\
& & 43 & $\mathrm{C}$ \\
\hline & & & \\
& & $\mathrm{N}$
\end{tabular}


femoral heads (Ohzono et al 1991), but some heads progress to collapse without apparent radiological changes. We used MRI because it can detect change in the bone marrow before radiography shows any abnormalities.

There was some regularity in the site and extent of the necrotic lesion; the larger lesions always included the sites of the smaller ones and the medial anterosuperior portion of the femoral head was most vulnerable. An analogy can be drawn between the site and the extent of the necrotic lesion in the femoral head and those in an ischaemic limb (Fig. 7), by considering the medial anterosuperior part of the head to be most peripheral in the intraosseous circulation. Any decrease in blood flow therefore causes necrosis, as in a limb, starting from the most peripheral zone.

MRI can show cross-sectional views on any selected plane without radiation exposure, and a stereoscopic image of the necrotic lesion in the femoral head can be obtained. Using this method, we found that the femoral heads in which the necrotic lesion occupied the major portion of the weight-bearing area had considerable risk of subsequent segmental collapse. Early MRI can predict the probability of subsequent segmental collapse of the femoral head.

This study was supported in part by a grant from the Japanese Ministry of Health and Welfare.

No benefits in any form have been received or will be received from a commercial party related directly or indirectly to the subject of this article.

\section{REFERENCES}

Bassett LW, Mirra JM, Cracchiolo A III, Gold RH. Ischemic necrosis of the femoral head: correlations of magnetic resonance imaging and histologic sections. Clin Orthop 1987; 223:181-7.

Glimcher MJ, Kenzora JE. The biology of osteonecrosis of the human femoral head and its clinical implications: II. The pathological changes in the femoral head as an organ and in the hip joint. Clin Orthop 1979; 139:273-312.

Kokubo T, Takatori Y, Ninomiya S, Nakamura T, Kamogawa $M$ Magnetic resonance imaging and scintigraphy of avascular necrosis of the femoral head: prediction of subsequent segmental collapse. Clin Orthop 1992; 277:54-60.

Lang P, Jergesen HE, Moseley ME, et al. Avascular necrosis of the femoral head: high-field-strength $M R$ imaging with histologic correlation. Radiology 1988; 169:517-24

Merle d'Aubigné R, Postel M, Mazabraud A, Massias P, Gueguen J. Idiopathic necrosis of the femoral head in adults. J Bone Joint Surg $[\mathrm{Br}] 1965 ;$ 47-B :612-33.

Mitchell DG, Steinberg ME, Dalinka MK, et al. Magnetic resonance imaging of the ischemic hip: alterations within the osteonecrotic, viable, and reactive zones. Clin Orthop 1989; 244:60-77.

Ohzono K, Saito M, Takaoka K, et al. Natural history of nontraumatic avascular necrosis of the femoral head. $J$ Bone Joint Surg [Br] 1991 ; 73-B :68-72.

Pocock SJ. Clinical trials: a practical approach. Chichester, etc: John Wiley \& Sons, 1983:84-6.

Robinson HJ Jr, Hartleben PD, Lund G, Schreiman J. Evaluation of magnetic resonance imaging in the diagnosis of osteonecrosis of the femoral head: accuracy compared with radiographs, core biopsy, and intraosseous pressure measurements. J Bone Joint Surg [Am] 1989; 71-A :650-63.

Stulberg BN, Levine M, Bawer TW, et al. Multimodality approach to osteonecrosis of the femoral head. Clin Orthop 1989;240:181-93.

Takatori Y, Kokubo T, Ninomiya S, Nakamura S, Okutsu I. Threedimensional structure of the low-signal-intensity area in magnetic resonance images of the femoral head with stage-I osteonecrosis. Kanto J Orthop Traumatol 1991 ; 22:296-300 [In Japanese]. 